\title{
ИЗМЕНЕНИЕ РЕГИОНАЛЬНОГО РЫНКА ТРУДА ПРОМЫШЛЕННОСТИ САНКТ-ПЕТЕРБУРГА В УСЛОВИЯХ ЦИФРОВОЙ ТРАНСФОРМАЦИИ
}

\author{
(c) 2021 Акимова Юлия Николаевна \\ кандидат психологических наук, доцент \\ Санкт-Петербургский политехнический университет Петра Великого, Россия, Санкт-Петербург
}

Цифровая трансформация детерминирует существенные изменения социально-экономических взаимодействий, включая рынок труда. В статье исследуется динамика рынка труда производственной сферы города федерального значения Санкт-Петербурга под влиянием современных вызовов. Анализируются целевые ориентиры и результаты регионального проекта «Поддержка занятости и повышение эффективности рынка труда для обеспечения роста производительности труда», который реализуется в Санкт-Петербурге с 2019 года. Выявлено, что регион отличается высокой экономической активностью, низким уровнем безработицы. Проанализированы и обобщены такие структурные элементы рынка труда мегаполиса: уровень занятости, напряженность рынка труда, уровень заработной платы, оборот рабочей силы в регионе. Диагностированы специфические тенденции востребованности ряда профессий на рынке труда Петербурга, проведён сравнительный анализ с данными по стране. Авторами составлен обобщённый портрет современного соискателя работы в Санкт-Петербурге, исходя из точек зрения разных рекрутинговых структур: коммерческой онлайн-рекрутинговой платформы HeadHunter и государственной Службы занятости СанктПетербурга. Выявлен возрастной состав соискателей в производственной сфере мегаполиса, подтверждающий общую пессимистичную тенденцию старения работоспособного населения России. В статье осуществлен анализ предложений цифровых платформ управления персоналом на уровне государства и предприятий, подтвержден возрастающий спрос регионального рынка на удалённую работу, проанализированы востребованные современным рынком труда Санкт-Петербурга компетенции. Сделан вывод о смене курса регионального рынка труда с аналогового на цифру в условиях цифровой доктрины.

Ключевые слова: рынок труда, человеческий капитал, хозяйствующие субъекты, компетенции, инвестиции в человеческий капитал, промышленность Санкт-Петербурга.

Город федерального значения СанктПетербург является мегаполисом, в котором на 01.03 .2021 г. постоянно проживает 5380,8 тыс. человек, из них в трудоспособном возрасте (мужчины - 16-60 л., женщины - 16-55 л., на 01.01.2020 г.) находится 3108,7 тыс. человек [8]. Санкт-Петербург - крупнейший промышленный центр России. Численность рабочей силы в Санкт-Петербурге (в среднем за январь 2020-март 2021 г.) составляет 3104,8 тыс. человек [8]. По данным Росстата, безработица в СанктПетербурге (по методологии МОТ) диагностирована на уровне $2,7 \%$. Этот показатель - один из самых низких среди субъектов России, для сравнения: в Москве $-3,1 \%$, по Российской Федерации в целом $-5,6 \%$. Номинальная средняя заработная плата, начисленная в феврале 2021 года, по официальным данным составила 71681 рублей, что на 9,5\% больше, чем в феврале 2020 года, и больше, чем по стране (51229 рублей) [9].
Средняя, с поправкой на инфляцию реальная заработная плата в Санкт-Петербурге составила $103,8 \%$ к уровню февраля предшествующего года. В обрабатывающем производстве СанктПетербурга выявлено наибольшее количество вакансий с начала года по конец апреля $-13,3 \%$ от общего количества вакансий, заявленных организациями в Службу занятости [4].

Бугаева Т.М. и Викторова Н.Г., исследовавшие особенности управления развитием энергетического комплекса Санкт-Петербурга, выделяют специфические особенности мегаполиса как сложной системы социально-экономических взаимодействий, к которым относятся наиболее развитые (по сравнению с малыми городами) социальная, производственная, энергетическая инфраструктуры. В мегаполисе имеются условия для разработки и внедрения инноваций за счет сосредоточения в нем широкого спектра научнообразовательных организаций, населения с вы- 
соким образовательным, квалификационным уровнем и инновационным потенциалом [1].

В докладе Ю.Сахаровой, директора HeadHunter Северо-Запад, на Международном Санкт-Петербургском Форуме труда - 2021 выделены основные тренды современного «соискательского» рынка труда России: растет популярность удаленной занятости, проектной и временной работы, расширяются области для фриланс-деятельности, расширяется география работодательского поиска, низкий уровень соискательской культуры и активности потенциальных кандидатов на найм, намечается тенденция на выравнивание зарплат в регионах по отношению к мегаполисам. Отмечается высокая конкуренция среди работодателей за работников, особенно за талантливую молодежь. Увеличивается значимость заботы компании о сотруднике: образование, здоровье, тренд на well-being. Вложения в HR становятся стратегическими (рост затрат на найм, онбординг, удержание персонала, сохранение и рост производительности труда). По мнению Ю. Сахаровой, на рынок труда СанктПетербурга влияет демография, миграционный отток, отложенный спрос, новые формы занятости. По исследованиям крупнейшего онлайнрекрутинговой платформы России HeadHunter, возрастная группа 20-24 года за последние 10 лет (с 2010г по 2020г) уменьшилась почти в два раза, а возрастная когорта 25-29 лет - на 21\%. Старшие когорты (50-59 лет) увеличиваются в численности и доминируют. Причем ситуация на ближайшие 5-10 лет продолжит усугубляться - когорты 10-14 лет и 15-19 лет очень малочисленны [10].

Одним из ключевых направлений стратегического развития Российской Федерации до 2025 года декларировано повышение производительности труда, в том числе посредством создания высокопроизводительных рабочих мест. Для этого в 2019 году запущен в реализацию национальный проект «Производительность труда и поддержка занятости». В 2019 году количество высокопроизводительных рабочих мест в стране увеличилось на 26,2\% и достигло 20,7 миллионов единиц [10]. Санкт-Петербург является участником этого национального проекта с 2019 года. Поставлена цель к 2024 году увеличить темпы роста производительности труда на средних и крупных предприятиях Санкт-Петербурга базовых несырьевых отраслей ежегодно на 5\%. В структуру указанного национального проекта входит региональный проект Санкт-Петербурга «Поддержка занятости и повышение эффективности рынка труда для обеспечения роста производительности труда» [5]. Целевыми ориентирами по повышению эффективности рынка труда в рамках реализации регионального проекта предусмотрено «создание системы обучения и переподготовки работников, отвечающее потребностям работодателей и соответствующее целям по повышению производительности труда; реализация мероприятий по повышению эффективности работы системы занятости населения» [6].

По данным Санкт-Петербургского государственного унитарного предприятия «СанктПетербургский информационно-аналитический центр» в I квартале 2020 года на рынке труда Санкт-Петербурга сохранялась высокая экономическая активность и низкий уровень безработицы. Численность занятых увеличилась, численность безработных увеличилась незначительно. Увеличился оборот рабочей силы на крупных и средних предприятиях СанктПетербурга по сравнению с I кварталом 2019 года. Число выбывших с предприятия сотрудников превысило число принятых на работу, аналогично IV кварталу 2019 года. На предприятиях 9 из 19 видов деятельности выявлено отрицательное сальдо приема-выбытия сотрудников [11].

По данным Службы занятости СанктПетербурга, напряженность на рынке труда, принятая как численность незанятых граждан, зарегистрированных в Службе занятости, из расчета на одну вакансию, в конце апреля 2021 года, уменьшилась, по сравнению с таким же периодом прошлого года (2,2 человека на вакансию) и составила 1,28 человека на одну вакансию [4].

Онлайн-рекрутинговой платформой HeadHunter введено в научно-практический оборот понятие «hһ.индекс - отношение количества активных резюме к вакансиям. Активные резюме - резюме, которые были видны работодателям за последние два месяца и которыми соискатели откликались на вакансии или просто обновляли или редактировали» [14]. За период март 2020 - март 2021 в России фиксируется скорее дефицит вакансий, нежели ищущих работу: наибольший показатель hh.индекса наблюдается среди высшего менеджмента, при этом отмечается стабильный рост ищущих работу в этой сфере: 12,9 hh.I в 2020 году и 18,1 hh.I в 2021 
году [10]. Интересно, что в Санкт-Петербурге картина совершенно иная: за сравнительный период с января по апрель 2020 и 2021 годов, hh.индекс, напротив, снижается: январь $-17,1$ и 15,8 , февраль 16,6 и 12,9, март 18,1 и 12,9, апрель 23,3 и 11,8 в 2020 и 2021 годах соответственно [15]. В производственной сфере по России данный показатель увеличивается и составляет 3,8 hh.I в 2020 году в сравнении с 5,8 hh.I в 2021 году [10]. А в Петербурге снова обратная история: за сравнительный период с января по апрель 2020 и 2021 годов, hh.индекс, напротив, снижается: январь $-5,8$ и 4,2, февраль 5,3 и 3,5, март 5,8 и 3,8, апрель 6,6 и 3,3 в 2020 и 2021 годах соответственно [15]. Таким образом, в целом по стране, исходя их данных показателей, мы наблюдаем перевес в сторону спроса на вакансии в указанных сегментах рынка труда. В Санкт-Петербурге также доминирует спрос на вакансии, при региональной тенденции к снижению количеств резюме на предложенную работодателями вакансию.

Современная структура вакансий по профессиональным сферам в регионе на платформе HeadHunter, иллюстрирующая каких специалистов чаще всего ищут работодатели и рассчитывающаяся по числу вакансий за последний месяц (апрель 2021 г), выглядит так: в ТОП-10 сфер с наиболее высоким спросом на специалистов, производство занимает почетное 3 место после сфер продаж и информационных технологий [15].

Исходя из данных онлайн-рекрутинговой платформы HeadHunter, портрет современного соискателя работы в производственной сфере в Санкт-Петербурге выглядит следующим образом. По гендерному признаку существенно доминируют мужчины (73\%). Возрастной состав соискателей в производственной сфере СанктПетербурга подтверждает общую пессимистичную картину России: в возрасте до 20 лет и от 20 до 25 лет нет претендентов на предложенные вакансии. Доминирует возрастная когорта в возрасте 26-35 лет, как среди мужчин, так и среди женщин. Предлагаемый соискателями опыт работы - 3-6 лет, как у мужчин, так и у женщин. $79 \%$ соискателей имеют высшее образование [15].

На основе статистического анализа зарегистрированных в органах службы занятости Санкт-Петербурга безработных граждан (49863 человека) был составлен портрет клиента Службы занятости на 31 марта 2021 года. По половому признаку больше женщин (62,9\%). Возрастная когорта 30-49 лет доминирует среди безработных (62,3\%). Среди молодежи (16-29 лет) безработных 15,2\% от общего числа, лиц предпенсионного возраста $-13,6 \%$. По образовательному статусу доминанта в зоне среднего профессионального образования $-55,7 \%$, причем доля выпускников профессиональных образовательных организаций (зарегистрированных в органах службы занятости в течение года после окончания учебного заведения) составляет $0,3 \%$. Доля лиц с высшим образованием - 25,6\%. Искали работу впервые, т.е. без опыта работы $14,7 \%$ безработных граждан. Большинство граждан, зарегистрированных в службе занятости, были уволены по собственному желанию (54,9\%) [7].

Ткаченко Е.А., Рогова Е.М., Хуажев А.А. исследовали системы управления интеллектуальным капиталом предприятий с высоким уровнем инновационной деятельности Санкт-Петербурга и Ленинградской области под влиянием цифровизации. Ученые выявили, что определяющее значение в эффективности и стратегической устойчивости предприятий имеет формирование и эксплуатация интернеториентированных цифровых платформ - площадок открытых инноваций [13]. По исследованиям Сурай Н.М. и ее коллег, выявлено, что на российских предприятиях имеет место изношенность основных фондов; недостаточный уровень социальной поддержки работников предприятий; низкий уровень конкурентной среды; использование устаревших форм и механизмов организации производств [12]. По мнению Денисенко В.Ю., Нарховой М.А., организация цифровой реформы на российских промышленных предприятиях не структурирована, перегружена новыми метриками и изменениями, что приводит к неудовлетворенности результатом, к конфликтным ситуациям на предприятии, и, как следствие, отказом от преобразований. Денисенко В.Ю., Нархова М.А. предлагают методику, описанную в кросс-функциональной диаграмме, способную зафиксировать и упростить алгоритмы проведения цифровых реформ в компании [3].

Неизбежность цифровой трансформации на предприятиях обусловлена еще и тем, что все более увеличивается спрос на удаленную работу. В Санкт-Петербурге, как и по всей России популярность удаленной работы растет. Онлайн-рекрутинговой платформой HeadHunter зафиксировано, что за четвертый квартал 2020 года, вакансий, связанных с удаленной рабо- 
той, в Петербурге было предложено в три раза больше, чем за четвертый квартал предшествующего года. За 11 месяцев (январь-ноябрь) 2020 года в Санкт-Петербурге количество вакансий для программистов и ИТ-разработчиков с возможностью удаленной работы возросло на $58 \%$ в сравнении с аналогичным периодом 2019 года. Но все же, несмотря на очевидный рост запроса рынка, предложение подобных вакансий невелико. На сайте hh.ru вакансий с отметкой «удалёнка» в ноябре 2019 года было предложено 2\% от общего количества опубликованных вакансий, в ноябре 2020 года уже 5\%. А это хоть и положительная динамика, но незначительная доля предложений на фоне других трендов рынка труда [2].

Под влиянием цифровой трансформации меняется и рынок компетенций. Растет спрос на работников с цифровыми навыками в самых разных сферах труда. Темпы роста вакансий с требованиями цифровых компетенций в СанктПетербурге опережают все другие. По данным HeadHunter, за 10 лет, с 2010 по 2020 год стремительно вырос запрос на цифровые компетенции от работодателей в Санкт-Петербурге - на $2479 \%$, а весь остальной рынок вакансий на 715\% за этот же период. Причем, в четвертом квартале 2020 года, по сравнению началом года отмечен еще рост на $46 \%$ на цифровые навыки [2].

Выводы. Санкт-Петербург - мегаполис со сложной системой социально-экономических взаимодействий, вовлекающей цифровые технологии во все сферы социально-экономической деятельности людей, в том числе, и рынок труда региона. С 2019 года в Санкт-Петербурге реализуется региональный проект «Поддержка занятости и повышение эффективности рынка труда для обеспечения роста производительности труда», входящего в национальный проект «Производительность труда и поддержка занятости» в качестве структурного элемента. В настоящее время регион отличается высокой экономической активностью. На 5380,8 тыс. постоянных жителей приходится 3104,8 тыс. работающих граждан. Уровень безработицы в СанктПетербурге - один из самых низких в стране. Уменьшилась напряженность на рынке труда Петербурга и на конец апреля 2021 года составляет 1,28 человека на одну вакансию. Оборот рабочей силы на крупных и средних предприятиях региона увеличился по сравнению с I кварталом 2019 года, но при этом, выявлено отрицательное сальдо приема-выбытия сотрудников. Номинальная начисленная средняя заработная плата -71681 рублей, а это выше, чем в целом по стране - 51229 рублей.

По данным онлайн-рекрутинговой платформы HeadHunter, выявлена специфическая тенденция в востребованности ряда профессий по России и в Санкт-Петербурге. Например, в высшем менеджменте по России растет количество резюме при уменьшении количеств вакансий, а в Петербурге выявлена обратная ситуация: количество ищущих работу в топ-менеджменте стремится к соответствию с предложениями от работодателя при общем сохранении доминирования в пропорции резюме над предложениями о работе. Аналогичная ситуация диагностирована и в производственной сфере. Таким образом, визуализируется запрос на вакансии в указанных сегментах рынка труда с разнообразием размещенных на сайте резюме. В СанктПетербурге также, как по России, доминирует спрос на вакансии, при региональной тенденции к снижению количества резюме на предложенную работодателями вакансию. Кроме того, в Санкт-Петербурге именно в производственной сфере осуществляется активный поиск работников работодателями, причем сфера производства нуждается в привлечении работников пока чуть меньше, чем сфера продаж и информационных технологий. Таким образом, у современного работодателя на сегодняшний день еще есть выбор для осуществления отбора персонала и пока нет ощутимого количественного дефицита в потенциальных работниках, причем по России этот выбор наиболее существенный, чем в Санкт-Петербурге, где намечена тенденция, которая со временем может привести к дефициту выбора потенциальных работников. Кроме того, в исследовании подтверждается общая пессимистичная картина России в отношении старения работоспособного населения, как и на территории Санкт-Петербурга в производственной сфере.

Портрет современного соискателя работы в Санкт-Петербурге выглядит различным с точки зрения разных рекрутинговых структур. Авторами статьи составлен обобщённый портрет соискателя работы в производственной сфере на основе данных коммерческой онлайн-рекрутинговой платформы HeadHunter и обобщённый портрет безработного на основе данных государственной Службы занятости 
Санкт-Петербурга. Соискатель, разместивший свое резюме на платформе HeadHunter, в обобщённом виде выглядит так: мужчина 26-35-ти лет, с высшим образованием и опытом работы - 3-6 лет. А современный безработный, состоящий на учете в Службе занятости СанктПетербурга - это, чаще всего, женщина 30-49 лет, со средним профессиональным образованием, по собственному желанию уволенная из организации с должности служащего, со средним периодом продолжительности безработицы около 5,8 месяцев.

Пандемия, вызванная коронавирусной инфекцией, ускорила движение в сторону цифровой трансформации социально-экономических отношений, и, в частности, системы управления. Предлагаются к использованию различные цифровые платформы, как для системы государственного управления занятостью населения, так и для управления персоналом предприятий. При этом исследователями диагностируются изношенность основных фондов предприятий, использование устаревших форм и механизмов организации производств, неструктурированность и перегруженность алгоритмов внедрения цифровых платформ, что существенно тормозит проведение цифровых реформ на предприятиях. Однако, неизбежность внедрения цифры на предприятиях осознается, в том числе, за счет детерминации возрастающего спроса на удаленную работу, хотя доля предложений от работодателей на «удалёнку» остается незначительным по сравнению с другими традиционными предложениями.

Цифровая трансформация изменяет и рынок компетенций. Ожидаемо возрастает интерес работодателей к собственно цифровым компетенциям, что подтверждается доминированием спроса на них по отношению ко всем другим запросам в поиске работников. Требуются сотрудники, обладающие критическим мышлением, способностью к анализу и решению проблем, готовые принять ответственность за решение, владеющие проектными технологиями, быстро выполняющие работы в проекте, инициативные и социально ориентированные. Таким образом, современному рынку труда требуется комбинация навыков: цифровых, интеллектуальных, эмоциональных, т.е. трансверсальных компетенций.

\section{Библиографический список}

1. Бугаева Т.М., Викторова Н.Г. 2020 Особенности управления развитием энергетического комплекса мегаполиса // Экономические науки, 2020, № 9 (190). С. 14-19. DOI: 10.14451/1.190.14

2. Востребованные профессии 2021: как пандемия изменила рынок труда в стране и Петербурге? https://78. ru/articles/2020-12-30/kak_peterburgskii_rinok_truda_perezhil_pandemiyu_v_2020_godu_i_kakih_tendencii_ zhdat_v_2021

3. Денисенко В.Ю., Нархова М.А. Управляющие воздействия на цифровую трансформацию предприятий вследствие кризиса, вызванного пандемией // Экономические науки, 2021, № 3 (196) стр. 71-73. DOI: $10.14451 / 1.196 .71$

4. Информация о положении на рынке труда и в сфере занятости населения Санкт-Петербурга январь-апрель 2021 года https://www.r21.spb.ru/empl/analytics_archive.htm?id=12006191@cmsArticle

5. Национальный проект «Производительность труда и поддержка занятости 2021 / Официальный сайт Комитета по труду и занятости населения Санкт-Петербурга http://rspb.ru/nacionalnye-proekty/nacionalnyjproekt-proizvoditelnost-truda-i-podderzhka-zanyatosti/

6. Паспорт регионального проекта «Поддержка занятости и повышение эффективности рынка труда для обеспечения роста производительности труда». Утвержден протоколом заседания проектного комитета по направлению «Производительность труда и поддержка занятости» в Санкт-Петербурге от 28.02.2020 № 80 / Официальный сайт Комитета по труду и занятости населения Санкт-Петербурга 2020 http://ktzn.gov.spb.ru/ nacionalnye-proekty/nacionalnyj-proekt-proizvoditelnost-truda-i-podderzhka-zanyatosti/regionalnyj-proektpodderzhka-zanyatosti-i-povyshenie-effektivnosti-ry/

7. «Портрет клиента» службы занятости на основе статистического анализа на 31 марта 2021 года https://www. r21.spb.ru/files/portal_upload/analitics/1kv2021.pdf

8. Рынок труда Санкт-Петербурга 2021 / Официальный сайт Комитета по труду и занятости населения СанктПетербурга http://rspb.ru/analiticheskaya-informaciya/rynok-truda-sankt-peterburga/

9. Рынок труда, занятость и заработная плата 2021 https://rosstat.gov.ru/labor_market_employment_ salaries?print $=1$ 
10. Сахарова Ю. 2021 Поток: СЗН для работодателей // Материалы Международного Санкт-Петербургского Форума труда - 2021.

11. Ситуация на рынке труда Санкт-Петербурга в январе-марте 2020 года. Аналитическая справка https://www. gov.spb.ru/static/writable/documents/2020/12/09.pdf

12. Сурай Н.М., Тараканов А. В., Орлов В.В., Кудрявцев В.В., Айдинов Х. Т. 2021 К вопросу о производительности труда в России и за рубежом // Экономические науки, 2020, №№ 10 (191). C. 155-162. DOI: 10.14451/1.191.155.

13. Ткаченко E.A., РоговаE.M., ХуажевА.А. 2020 Трансформация подходов к управлению интеллектуальным капиталом под влиянием цифровизации // Экономические науки, 2020, № 10 (191). C. 163-167. DOI: 10.14451/1.191.163

14. hh.Индекс. Статистика по России 2021 // https:/stats.hh.ru/?utm_source=hh.ru\&utm_medium=article\&utm_ campaign=article_index

15. hh.Индекс. Статистика по России. Северо-Западный федеральный округ. Санкт-Петербург 2021 // https:// stats.hh.ru/?utm_source=hh.ru\&utm_medium=article\&utm_campaign=article_index 